\title{
Short Communication: Diurnal Feeding Pattern of Lactating Dairy Cows
}

\author{
T. J. DeVries, ${ }^{*}$ M. A. G. von Keyserlingk, ${ }^{*}$ and K. A. Beauchemin† \\ *Animal Welfare Program, Faculty of Agricultural Sciences, \\ The University of British Columbia, \\ 2357 Main Mall, Vancouver V6T 1Z4, Canada \\ †Agriculture and Agri-Food Canada, P.O. Box 3000, \\ Research Centre, Lethbridge, Alberta T1J 4B1, Canada
}

\section{ABSTRACT}

The objectives of this research were to: 1) describe the diurnal variation in feed alley attendance patterns of lactating dairy cows, 2) describe the sources of variation in these patterns, and 3) determine the effects of altering the feed push-up schedule on these patterns. An electronic monitoring system was used to record individual cow presence (6-s resolution) at the feed alley for 24 cows housed in a free-stall barn. Cows were subjected to 2 feeding schedules: 1) baseline schedule, where cows were fed at 0600 and $1515 \mathrm{~h}$ and feed was pushed closer to the cows at 1100 and $2130 \mathrm{~h}$; and 2) experimental schedule, where 2 additional feed pushups at 0030 and $0330 \mathrm{~h}$ were added to the baseline schedule. With the data collected from the monitoring system, description of the feed alley attendance patterns on a per minute basis of the group of cows was undertaken. Feed alley attendance was consistently higher during the day and early evening compared with the late night and early morning hours. The greatest percentage of cows attending the feed alley was seen after the delivery of fresh feed and the return from milking. The addition of extra feed push-ups in the early morning hours did little to increase feeding activity. It can be concluded that milking and delivery of fresh feed had a much greater affect on the diurnal pattern of feed alley attendance than did the feed push-ups.

(Key words: feeding behavior, dairy cow, feeding pattern, push-up)

Traditionally, cattle have been thought to exhibit diurnal feeding patterns whereby they consume the majority of their daily DMI between dawn and dusk (Hafez and Boissou, 1975), and more specifically, referred to as crepuscular feeding, with their largest and most extensive meals occurring at sunrise and sunset (Ray and Roubicek, 1971; Hafez and Boissou, 1975; Ruckebusch

Received July 10, 2003.

Accepted August 7, 2003

Corresponding author: T. DeVries; e-mail: trevorjd@interchange. ubc.ca. and Bueno, 1978). The majority of research on the feeding patterns of ruminants has relied on the use of visual observations obtained when viewing ruminants on pasture. However, management of North American dairy farms has moved from traditional extensive pasture systems to highly specialized intensive systems where cows are kept indoors in free-stall environments and fed a TMR.

There have been extensive reviews (Albright, 1993; Grant and Albright, 1995, 2000) of the feeding behavior of lactating cows housed in freestall environments and fed a TMR. Grant and Albright (2000) concluded that management factors such as grouping, feeding system design and apparatus, composition and physical characteristics of the feed being consumed, as well as social hierarchy and competition for food and water, are all factors that influence the feeding behavior of cattle. Unfortunately, there has been limited research (Tanida et al., 1984; Menzi and Chase, 1994; Wagner-Storch and Palmer, 2003) on how lactating cows housed in free-stall barns pattern their feeding during the course of the day and what causes variations in these patterns.

Dairy cows housed in a free-stall barn are commonly fed a TMR once or twice daily. The natural tendency for cows to continually sort the feed and push it away while eating results in much of the feed being tossed forward where it is no longer within reach. This becomes a particular problem when feed is delivered via a feed alley and thus producers commonly push the TMR closer to the cows (push-up) in between feedings as a means of ensuring that cows have continuous access to the feed. There is limited research describing the feeding patterns and the behavioral response to changes in push-up schedules of group-housed lactating dairy cattle fed twice daily. Therefore, the objectives of this study were: first, to describe the diurnal variation in feed alley attendance patterns of lactating dairy cows, second, to describe the sources of variation, and third, to determine the effects of increasing the number of feed push-ups on these patterns.

The study was carried out at The University of British Columbia Dairy Education and Research Center (Agassiz, Canada). Eleven primiparous and 13 multiparous 


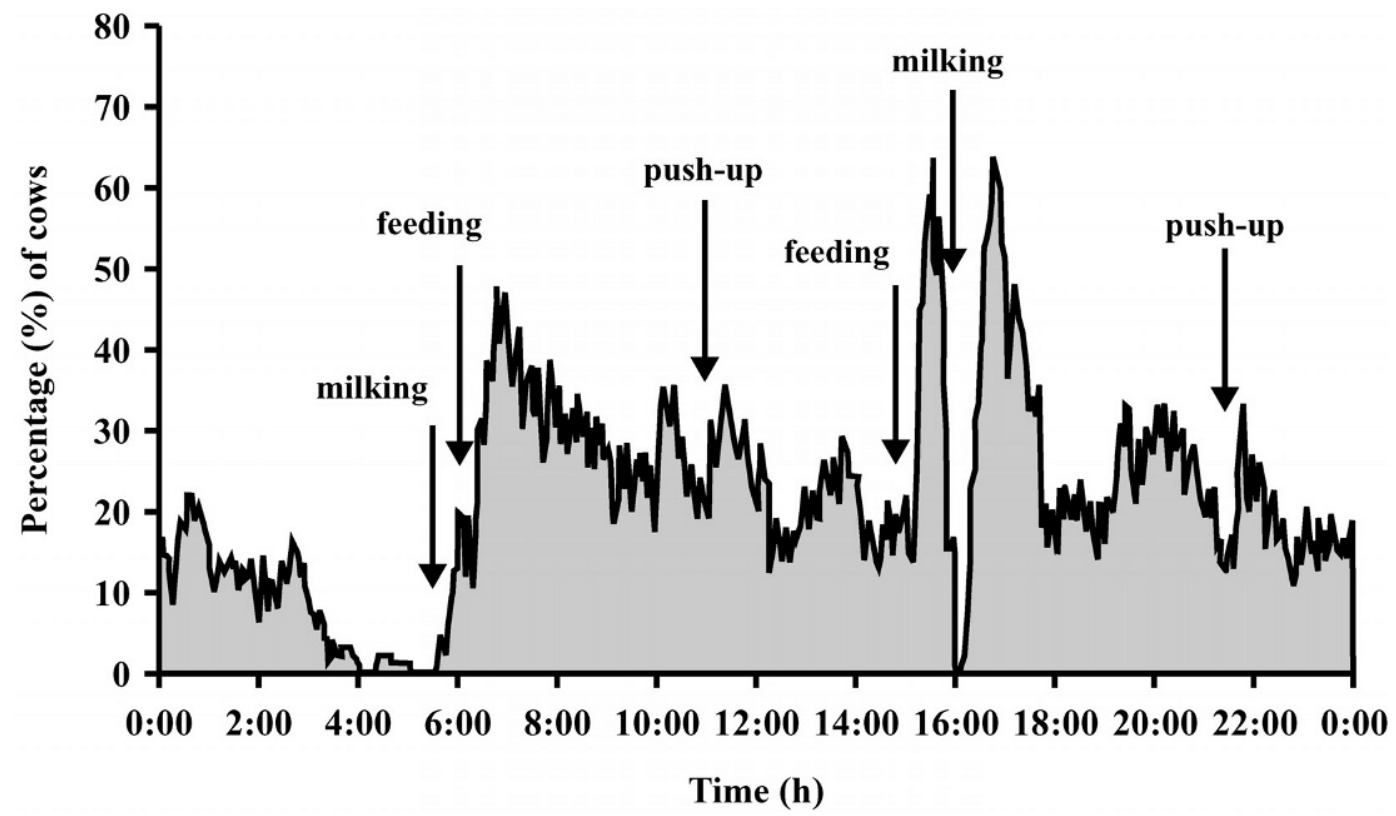

Figure 1. Percentage of 24 cows present at the feed alley over a 24 -h period (percentage for each 60 -s interval during the day) averaged over $4 \mathrm{~d}$ while cows were on the baseline feeding schedule.

(mean parity $=4.0 ; \mathrm{SD}=1.1$ ) Holstein cows were used in this study and were cared for under the Canadian Council on Animal Care (1993) guidelines. Animals were $95 \pm 17$ (mean \pm SD) DIM at the start of the study and produced an average $38.8 \pm 9.4 \mathrm{~kg} \cdot \mathrm{d}^{-1}$ of milk over the course of the study. They were fed a TMR consisting of $20 \%$ corn silage, $20 \%$ grass silage, $7 \%$ alfalfa hay, $3 \%$ grass hay, and $50 \%$ grain concentrate mash on a DM basis formulated according to the NRC (2001). The TMR was provided in a feed alley with neck rail access; there was $0.6 \mathrm{~m}$ of feeding space per cow. The cows were group-housed in a pen containing 24 free-stalls deep bedded with sand. Cows were milked twice daily, between 0515 and $0545 \mathrm{~h}$ and between 1600 and 1630 h. The study took place in late November with sunrise and sunset occurring at 0730 and $1630 \mathrm{~h}$, respectively, at the outset of the study.

Cows were subjected to 2 different feeding schedules. In the baseline period, cows were fed at 0600 and 1515 $\mathrm{h}$, and feed was pushed closer to the cows at 1100 and $2130 \mathrm{~h}$. This schedule was maintained for a period of $4 \mathrm{~d}$. The experimental feeding schedule was then implemented for $5 \mathrm{~d}$, whereby the feeding and push-up times used in baseline schedule were maintained plus 2 additional push-up times were added at $0030 \mathrm{~h}$ and 0330 $\mathrm{h}$. These times were chosen because preliminary observations indicated little feeding activity at these times. Following this, the animals were returned to the baseline period feeding schedule for an additional $4 \mathrm{~d}$. Length of the periods reflected sufficient days to estab- lish no changes in behavior within each feeding schedule. Feeding behavior was monitored as described by DeVries et al. (2003) using an electronic feed alley monitoring system (GrowSafe Systems Ltd., Airdrie, AB, Canada) that recorded individual cow presence (hits; 6 -s resolution) at the feed alley.

The data were used to determine the feed alley attendance patterns for the group, as well as the individual cow feeding activity (number of hits per time period) as described by DeVries et al. (2003). Feeding activity was recorded for number of hits per day and number of hits in the first hour following feeding and feed pushups (this included the hour past 0030 and $0330 \mathrm{~h}$ during the baseline period). Due to a technical difficulty with the equipment, data were not collected for the third day of the experimental period. Feeding activity data were averaged to generate means for each cow for both the baseline and experimental periods for statistical comparisons. All inferential comparisons between treatment periods were done within cow by paired $t$ tests with 23 degrees of freedom (SAS, 1985). No differences between the feeding activity data of the two periods where the baseline feeding schedule was used were found; therefore, only the data from the initial time period was used in further analysis.

The percentage of animals present at the feed alley during each 60 -s interval within $24 \mathrm{~h}$ (i.e., 1440 observations) averaged across the $4 \mathrm{~d}$ of the baseline schedule is presented in Figure 1. This figure indicates that although cows were present at the feed alley nearly every 


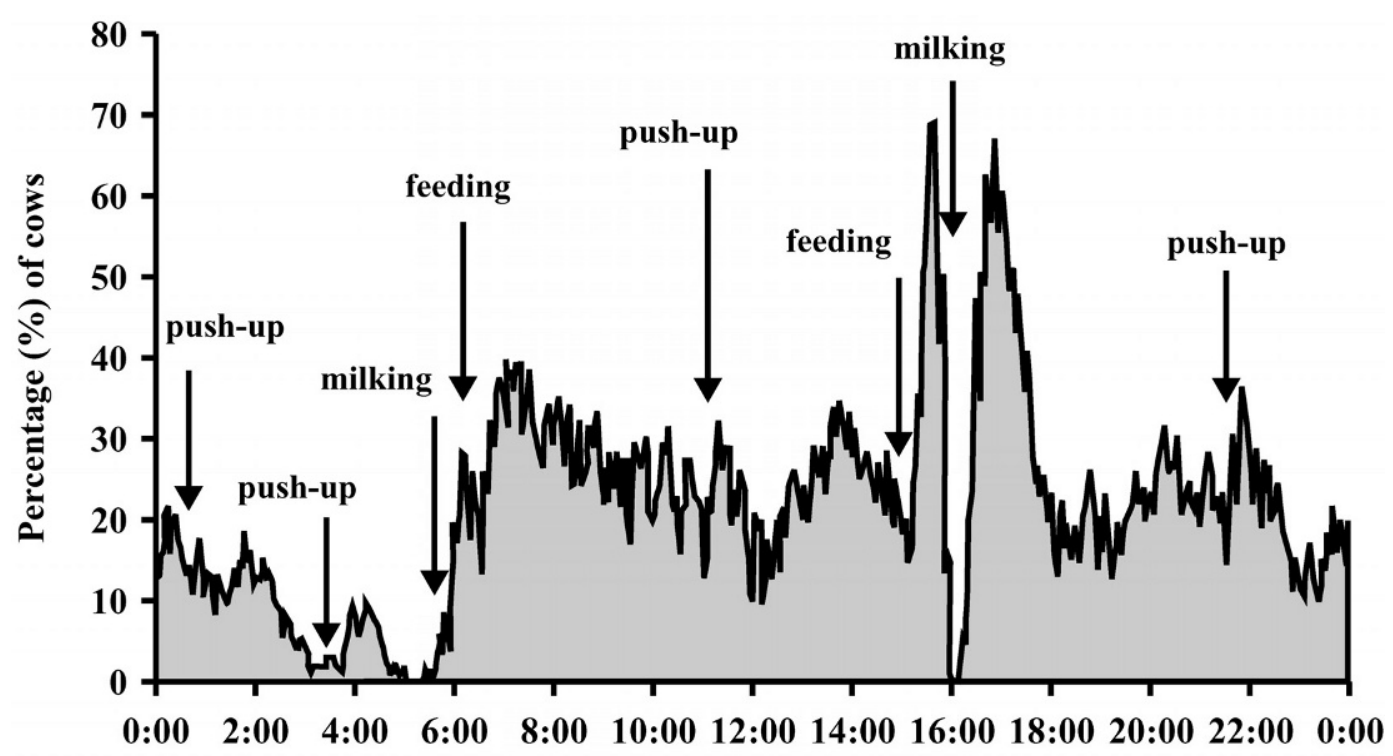

Time (h)

Figure 2. Percentage of 24 cows present at the feed alley over a 24-h period (percentage for each 60-s interval during the day) averaged over $4 \mathrm{~d}$ while cows were on the experimental feeding schedule.

minute of the day the highest percentage was during the daytime and the early evening $(0600$ to $1800 \mathrm{~h})$ and the lowest percentage during the late evening and early morning hours. These findings are similar to that reported by Tanida et al. (1984), who found that the majority of feeding activity of free-stall housed cows occurred during the day, with a correspondingly strong reduction in feeding activity during the night.

The sources of variation in feed alley attendance patterns are also indicated in Figure 1. There was a dramatic increase in the number of animals present at the feed alley immediately following the morning delivery of fresh feed and milking period. Interestingly, this response was even greater following the afternoon feeding and milking events. Similar observations in eating activity of dairy cows housed in free-stall barns following feeding and milking activities were reported by Tanida et al. (1984) and Wagner-Storch and Palmer (2003). The response in the percentage of animals present at the feed alley in the hour immediately following each of the feed push-ups was not nearly as dramatic as the response to milking and feeding (Figure 1). Although Menzi and Chase (1994) noted that cows increased bunk usage after feed push-up, delivery of fresh feed, and milking, they concluded that both feed push-ups and feeding tended to have "minor and brief effects" in comparison to milking, on feed bunk attendance. In contrast to that reported by Menzi and Chase (1994), the large peaks in the current study only corresponded to times of milking and delivery of fresh feed. The acts of milking and delivery of fresh feed do not occur simultaneously in all commercial situations; therefore feeding patterns may be different in those situations. This may also be true for those operations that feed at a different frequency than twice daily. However, there is insufficient research to indicate how feeding patterns change when feeding and milking times do not coincide or when feeding frequency is altered.

Previous attempts to plot feed alley attendance patterns have been marred by visual observations and limited data points. Menzi and Chase (1994) used only 1 $\mathrm{d}$ of data and recorded at 15-min intervals a subjective score for the number of cows at the feed alley. Tanida et al. (1984) also attempted to pattern the eating behavior of free-stall housed-cows; however, they too only presented a single day of data and used 10-min periods to summarize the number of animals feeding over the course of the day. In a more recent paper, WagnerStorch and Palmer (2003) also based their feed alley attendance results on a limited number of observations $(1 \mathrm{~d} / \mathrm{mo}$ with a scanning interval of 1 observation per hour) taken over $9 \mathrm{mo}$. In the present study, the use of multiple days of data and a 6-s electronic scanning method allowed for a much more accurate calculation of the number of animals present at the feed alley for many short time intervals throughout the day of dairy cows housed in a free-stall barn.

In Figure 2 the percentage of animals present at the feed alley averaged across the $4 \mathrm{~d}$ of the experimental schedule is presented. Visual comparison of this figure 
with Figure 1 indicates that the cows continued to be present at the feed alley primarily during the day, with a reduction in attendance at night. Even though there was no significant change $(P=0.29)$ in daily feeding activity, there appear to be small numerical changes in percentages of cows feeding at different times during the day. There was a slight increase in the percentage of cows at the feed alley after the 0030 and $0330 \mathrm{~h}$ feed push-ups. However, because there are so few animals present at the feed alley at these times, such a small response indicates that these extra feed push-ups would have little impact in terms of increasing feeding activity. Analysis of individual cow feeding activity during the hour immediately following the 0030 and $0330 \mathrm{~h}$ push-ups indicated no significant $(P=0.07$ and 0.14 , respectively) change in feeding activity at these times. There appears to be a slight reduction in attendance following the morning feeding during the experimental feeding schedule (Figure 2). However, there was no significant $(P=0.17)$ decrease in feeding activity in the hour immediately following the morning feeding when the 0030 and $0330 \mathrm{~h}$ feed push-ups were added. No other changes in feeding activity were found for any of the other after feeding and after push-up time periods during the experimental feeding period.

In summary, an electronic feed alley monitoring system can be used to accurately describe the diurnal feedalley attendance patterns of a group of high producing dairy cows housed in a free stall barn. Large variations in daily feed alley attendance were found over the course of the day, particularly after the delivery of fresh feed and the return of the cows from milking. The addition of extra feed push-ups in the early morning hours did little to alter the diurnal pattern of feed alley attendance and did not increase feeding activity.

\section{ACKNOWLEDGMENTS}

We thank the staff and students at The University of British Columbia's Dairy Education and Research
Centre and the University's Animal Welfare Program. Trevor DeVries was supported by a Natural Sciences and Engineering Research Council of Canada Postgraduate Scholarship. The project was funded by the Natural Sciences and Engineering Research Council of Canada, through the Industrial Research Chair in Animal Welfare, and by contributions from the Dairy Farmers of Canada and many other donors listed at http:// www.agsci.ubc.ca/animalwelfare.

\section{REFERENCES}

Albright, J. L. 1993. Feeding behavior of dairy cattle. J. Dairy Sci. 76:485-498.

Canadian Council on Animal Care. 1993. Guide to the Care and Use of Experimental Animals. Vol. 1. E. D. Olfert, B. M. Cross, and A. A. McWilliam, ed. CCAC, Ottawa, ON, Canada.

DeVries, T. J., M. A. G. von Keyserlingk, D. M. Weary, and K. A. Beauchemin. 2003. Measuring the feeding behavior of lactating dairy cows in early to peak lactation. J. Dairy. Sci. 86:3354-3361.

Grant, R. J., and Albright, J. L. 1995. Feeding behavior and management factors during the transition period in dairy cattle. J. Anim. Sci. 73: 2791-2803.

Grant, R. J., and J. L. Albright. 2000. Feeding behaviour. Pages 365382 in Farm Animal Metabolism and Nutrition. J. P. F. D’Mello, ed. CABI Publishing, Wallingford, Oxon, UK.

Hafez, E. S. E., and M. F. Boissou 1975. The behaviour of cattle. Pages 203-245 in The behaviour of domestic animals. 3rd ed. E. S. E. Hafez, ed. Bailliere Tindall, London, UK.

Menzi, W., Jr., and L. E. Chase. 1994. Feeding behavior of cows housed in free stall barns. Pages 829-831 in Dairy Systems for the 21st Century. Am. Soc. Agric. Eng., St. Joseph, MI.

National Research Council. 2001. Nutrient Requirements for Dairy Cattle. Natl. Acad. Sci. Washington, DC.

Ray, D. E., and C. B. Roubicek, 1971. Behavior of feedlot cattle during two seasons. J. Anim. Sci. 33:72-76.

Ruckebusch, Y., and L. Bueno. 1978. An analysis of ingestive behaviour and activity of cattle under field conditions. Appl. Anim. Ethol. 4:301-313.

SAS User's Guide: Statistics, Version 5 Edition. 1985. SAS Inst., Inc., Cary, NC.

Tanida, H., L. V. Swanson, and W. D. Hohenboken. 1984. Effect of artificial photoperiod on eating behavior and other behavioural observations of dairy cows. J. Dairy Sci. 67:585-591.

Wagner-Storch, A. M., and R. W. Palmer. 2003. Feeding behavior, milking behavior, and milk yields of cows milked in a parlor versus an automatic milking system. J. Dairy. Sci. 86:1494-1502. 